\title{
AN INNOVATIVE WAY FOR EXTRACTION OF ESSENTIAL OIL COMPONENTS FROM PIMPINELLA ANISUM L. FRUITS
}

\author{
NIKOLAY N. BOYKO ${ }^{1 \mathrm{~A}^{*}}$, DMITRIY I. PISAREV ${ }^{1 \mathrm{~B}}$, ELENA T. ZHILYAKOVA ${ }^{1 \mathrm{C}}$, ANASTASIYA YU. MALYUTINA ${ }^{1 \mathrm{~B}}$, OLEG \\ O. NOVIKOV ${ }^{2}$, VICTORIA YU. KUZNIETSOVA ${ }^{3}$, RITA V. SAHAIDAK-NIKITIUK ${ }^{3 B}$, MYKOLA YE. BLAZHEYEVSKIY ${ }^{3}$, \\ OLEG S. SHPYCHAK ${ }^{3 D}$, NATALIA A. SUSHCHUK ${ }^{4}$
}

\begin{abstract}
${ }^{1}$ Laboratory of technology of drugs, bDepartment of General chemistry, cDepartment of Pharmaceutical Technology, Belgorod National Research University, 85, Pobedy St., Belgorod, Russia, 308015, ${ }^{2}$ Test Department "Drugs quality control center" of the Shared Research and Education Center, Peoples' Friendship University of Russia, 8/2, Miklukho-Maklay St., Moscow, Russia, 117198, ${ }^{3}$ Department of Chemistry of Natural Compounds, bDepartment of Processes and Apparatuses of Chemical and Pharmaceutical Industries, cDepartment of Physical and Colloid Chemistry, ${ }^{D}$ Department of Industrial Pharmacy and Economy Institute for Advanced Training of Pharmacy Specialists, National University of Pharmacy, 53, Pushkinska St., Kharkiv, Ukraine, 61002, ${ }^{4}$ Department of Technology of Drugs, Odessa National Medical University, 2, Valikhovsky lane, Odessa, Ukraine, 65000.
\end{abstract}

Email: boykoniknik@gmail.com

Received: 01 Mar 2019, Revised and Accepted: 17 Apr 2019

\section{ABSTRACT}

Objective: The aim of this article was to test the hypothesis about the possibility for extraction of essential oil components from the plant raw material (PRM) by the example of Pimpinella anisum L. fruits with two different perfluoro organic solvents, Novec 1230 and Novec 7100.

Methods: For the studies, we used Pimpinella anisum L. fruits ground to obtain particle size between 0.1 and $0.5 \mathrm{~mm}$. The study of qualitative and quantitative content of the extracts was carried out by the following method: simple maceration, PRM: extractant ratio 1:10 w/v; and circulation method for extraction using Soxhlet extractor, PRM: extractant ratio 1:5 w/v. Qualitative analysis of extracts was carried out by gas chromatography-mass spectrometry (GC-MS) method. Quantitative analysis of trans-anethole in the extracts was carried out by reverse phase highperformance liquid chromatography (RP HPLC) method.

Results: The largest yield of anethole was observed for n-hexane, $84 \pm 4 \%$, and for Novec $7100,81 \pm 4 \%$. In case of Novec 1230 solvent, the yield of anethole was noted to be three times less, $32 \pm 2 \%$. The yield of anethole under the conditions of solvents (Novec 1230 and Novec 7100 ) circulation method was up to $94 \pm 5 \%$ within two hours.

Conclusion: Adequacy of the working hypothesis about the possibility for extraction of essential oil components from Pimpinella anisum L. fruits by two different perfluoro organic solvents, Novec 1230 and Novec 7100, was verified experimentally. In the context of the solvents tested, it was found that the level of fluorination of the solvent's molecule had a great influence on its extraction properties in regard to anethole and vegetable oil.

Keywords: RP HPLC, GC-MS, Essential oil, Anethole, Pimpinella anisum L., Novec 1230, Novec 7100, n-hexane

(C) 2019 The Authors. Published by Innovare Academic Sciences Pvt Ltd. This is an open-access article under the CC BY license (http://creativecommons.org/licenses/by/4.0/) DOI: http://dx.doi.org/10.22159/ijap.2019v11i4.32825

\section{INTRODUCTION}

At this date, several different ways (technologies) for separation of essential oil from the essential-oil-bearing plant raw material (PRM) are well known, such as hydrodistillation by water steam, microwave-assisted distillation, and extraction using different types of organic solvents and liquefied gases, etc [1-3].

Herewith, the leading-edge method for separation of essential oil components from the PRM is the technology of supercritical fluid extraction with carbon dioxide $[4,5]$.

It should be noted that using freons is no less promising method for extraction of essential oils from the PRM. However, these technologies have significant disadvantages: the necessity to use special equipment that should work under overpressure, the necessity to use an electrical refrigerator for extractant vapor condensation, the necessity to use additional energy for refrigerator work, and low separation selectivity between essential and vegetable oils, etc.

As a result of literature and patent search, the authors found that researchers from the USSR in 1980-90s, as well those from France, the USA, and Belgium in 2000-2006, had determined experimentally unique extraction properties in some perfluoro organic solvents [6-9].

Among the solvents, the following ones are mentioned: perfluoro cyclo butane (RC318), pentafluoro butane, perfluoro butyl methyl ether (Novec 7100), perfluoro butyl ethyl ether (Novec 7200), decafluoropentane, and perfluorohexane.
From the literature data, it is known that perfluoro organic solvents are almost identical and some of their properties are even better than those of liquefied gases; in addition, they have both, hydrophobic and lipophobic properties [10-13]. For example, some of them have the heat of evaporation values from 88 to $130 \mathrm{~J} / \mathrm{kg}$ against those for freon 227 ea, RC318 and carbon dioxide being 133, 117, and $155 \mathrm{~J} / \mathrm{kg}$, respectively. However, unlike liquefied gases, perfluoro organic solvents have relatively high values of boiling point, over $34^{\circ} \mathrm{C}$.

Therefore, some perfluoro organic solvents are highly promising for use in phytotechnology for extraction of some types of lipophilic substances including essential oil components from the PRM.

Pimpinella anisum L. fruits are one of the promising types of essential-oil-bearing plant raw materials. It is conditioned by the fact that the content of essential oil in this PRM is up to $3 \%$ (transanethole up to $90 \%$ ), as well as vegetable oil-up to $23 \%$, proteinsup to $18 \%$, carbohydrates-up to $5 \%$, vitamins, minerals, etc [14].

The most useful component in Pimpinella anisum L. fruits is an essential oil, which is widely used in medicine, food, and alcoholic beverage industries $[15,16]$.

In the Russian Federation, two perfluoro organic solvents, Novec 1230 and Novec 7100, are commercially available; and they have very promising physical and chemical, toxicological and ecological parameters [11].

Therefore, based on literature and patent search, we make a working hypothesis that perfluoro organic solvents may be used in 
phytotechnology for extraction of essential oils from plant raw materials.

The aim of this article was to test the hypothesis about the possibility for extraction of essential oil components from the plant raw material by the example of Pimpinella anisum L. fruits with two different perfluoro organic solvents, Novec 1230 and Novec 7100.

\section{MATERIALS AND METHODS}

For the studies, we used Pimpinella anisum L. fruits bought in LLC Pharmaceutical shop "Medicinal plants", Kharkiv, Ukraine, lot No. 135117, best before $08 / 2020$. The plant raw material satisfied the requirements of pharmacopeia monograph 01/2012:0262 "Aniseed" of European Pharmacopoeia [17]. Immediately before the experiment, the PRM was ground to particle fraction between 0.1 and $0.5 \mathrm{~mm}$ using high-speed multifunction grinder HC-500Y, China.

\section{Preparation of extracts}

The study of qualitative and quantitative content of the extracts was carried out by the following method: 1.0 gram (precisely weighed amount) of the ground PRM was transferred into vials and $10.0 \mathrm{ml}$ of the solvent (PRM: extractant ratio 1:10 w/v) were added. Then the vials were sealed and allowed to macerate at room temperature $24 \pm 1{ }^{\circ} \mathrm{C}$ for $24 \mathrm{~h}$. After maceration, the extracts were decanted and analyzed using gas chromatography-mass spectrometry (GC-MS) and reverse phase high-performance liquid chromatography (RP HPLC) methods.

A circulation method for extraction using Soxhlet extractor was employed at the following conditions: 5.0 gram (precisely weighed amount) of the ground PRM were added into the extractor, then $25.0 \mathrm{ml}$ of the solvent (PRM: extractant ratio 1:5 w/v) were added, and circulation of the extractant was carried out for a defined period of time.

Then the extract was decanted, the extractant was evaporated and diluted with ethyl acetate up to $10.0 \mathrm{ml}$ (precisely weighed amount).
This ethyl acetate solution was divided into two parts, approximately $5.0 \mathrm{ml}$ each (precisely weighed amount).

The one part was analyzed for oil content by the gravimetric method, and the second part was analyzed for anethole content by RP HPLC method. For this purpose, $2.0 \mathrm{ml}$ (precisely weighed amount) of ethyl acetate extract was added into a 5.0-ml flask, ethyl acetate was evaporated by air blowing for 10-15 min, then ethanol $96 \%$ was added and mixed, the mixture was centrifuged at 3,000 rpm for $30 \mathrm{~min}$ in order to separate ethanolic and oil fractions.

Ethanolic solution was centrifuged for the second time at 13,000 rpm for $5 \mathrm{~min}$ and it was analyzed by RP HPLC method at an analytical wavelength of $284 \mathrm{~nm}$.

\section{GC-MS method of analysis}

Qualitative analysis of extracts was carried out by GC-MS method using equipment GCMS-QP2010 Ultra, by Shimadzu, Japan. Column: Zebron ZB-5MS, length $30 \mathrm{~m}$, inside diameter $0.25 \mathrm{~mm}$, film thickness $0.25 \mu \mathrm{m}$; liquid phase: 5\% phenyl-arylene, $95 \%$ dimethylsiloxane; temperature settings: from $70 \mathrm{C}^{\circ}$ to $325 / 350 \mathrm{C}{ }^{\circ}$. Gas-carrier was helium with the stable flow: $3.0 \mathrm{ml} / \mathrm{min}$. The injection volume was $1 \mu$ l. Detection was carried out in full ion current regime (SCAN) in the range of $\mathrm{m} / \mathrm{z}$ from 30 to $500 \mathrm{Da}$. Before the test, ethyl acetate extract was filtered through a $0.45 \mu \mathrm{m}$ filter.

\section{RP HPLC method of analysis}

Quantitative analysis of trans-anethole in the extracts was carried out by RP HPLC method using Agilent Technologies equipment, Agilent 1200 Infinity series, the USA. The process of a RP HPLC analysis was carried out under the following conditions: mobile phase (a): $1 \%$ water solution of formic acid, (b): ethanol $96 \% \mathrm{v} / \mathrm{v}$ in linear gradient elution; chromatographic column: Supelco Ascentis express C18, length $100 \mathrm{~mm}$, inside diameter $4.6 \mathrm{~mm}$, particle size $2.7 \mu \mathrm{m}$; mobile phase velocity: 0.5 $\mathrm{ml} / \mathrm{min}$; temperature of the chromatographic column: $+35{ }^{\circ} \mathrm{C}$; sample volume: $1 \mu \mathrm{l}$. RP HPLC analysis conditions were the same as in the work of Zhilyakova et al. [18].

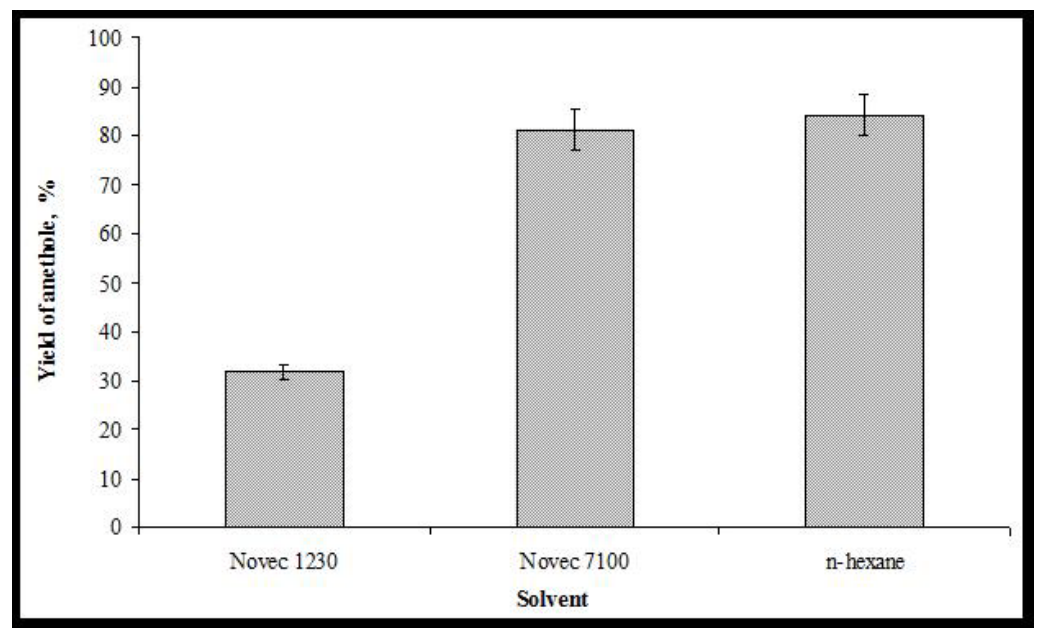

Fig. 1: Yield of anethole from the PRM at maceration. PRM: extractant ratio $1: 10 \mathrm{w} / \mathrm{v}$, temperature $24 \pm 1^{\circ} \mathrm{C}$, time of maceration $24 \mathrm{~h}$. Repeat counts $n=3$ and significance level $P=0.95$

Table 1: Main parameters of the validation method of analysis and suitability of HPLC system for determination of trans-anethole

\begin{tabular}{lll}
\hline Parameter & Pharmacopoeia limitation [17] & Trans-anethole* \\
\hline Retention time $\left(\mathrm{t}_{\mathrm{R}}\right), \min$ & - & $15.7 \pm 0.3$ \\
Asymmetry coefficient $(\mathrm{T})$ & $\leq 2.0$ & 0.85 \\
Separation coefficient $\left(\mathrm{R}_{\mathrm{s}}\right)$ & $\geq 1.5$ & 3.62 \\
Theoretical plates number $(\mathrm{N})$ & $\geq 1000$ & 36057 \\
RSD of peak's area, $\%$ & $\leq 2.0$ & 1.1 \\
LOD, g/ml & - \\
LOQ, g/ml & - & $5.8 \cdot 10^{-5}$ \\
Determination coefficient, $r^{2}$ & $\geq 0.99$ & $1.7 \cdot 10^{-4}$ \\
Calibration linear equation, $C(\mathrm{~g} / \mathrm{ml})=f(S(\mathrm{mAU} \cdot \mathrm{s}))$ & - & 0.9999 \\
\hline
\end{tabular}

${ }^{*}$ Note. The mean value and its confidence interval (mean \pm SEM) are calculated with repeat counts $n=3$ and significance level $P=0.95$. 
Suitability and validation parameters of the chromatographic method

The main parameters of the validation method of analysis and suitability of RP HPLC system for determination of trans-anethole are presented in table 1 .

\section{Chemicals}

Novec 1230, Novec 7100 (3M company, USA), and n-hexane (chemically pure grade, Component-Reactive, Russia) were used as solvents. As a reference substance, we used trans-anethole SigmaAldrich, Merck, content $\geq 99.0 \%$. CAS Number: 4180-23-8.

\section{RESULTS}

In the first part of our experiments, we studied the yield of anethole into different solvents (Novec 1230/7100 and n-hexane). The results obtained are presented in fig. 1.
As can be seen from the data presented in fig. 1, the largest yield of anethole is observed for n-hexane, $84 \pm 4 \%$, and for Novec 7100 , $81 \pm 4 \%$. In case of Novec 1230 solvent, the yield of anethole it noted to be three times less, $32 \pm 2 \%$.

These results can be explained by the structure of anethole and solvent molecules. For example, the hydrocarbon skeleton of Novec 1230 solvent's molecule has the maximum level of fluorine saturation and, thus, has maximum lipophobic properties, and a methoxy group is present in the hydrocarbon skeleton of Novec 7100 solvent's molecule, it adds more lipophilic properties and makes it closer to n-hexane.

A typical chromatogram of Novec 7100 extract obtained by GC-MS method is presented in fig. 2.

As can be seen from GC-MS chromatogram presented in fig. 2, there are four dominant compounds in Novec 7100 extract. Similar results were obtained for Novec 1230, see the fig. 3 .

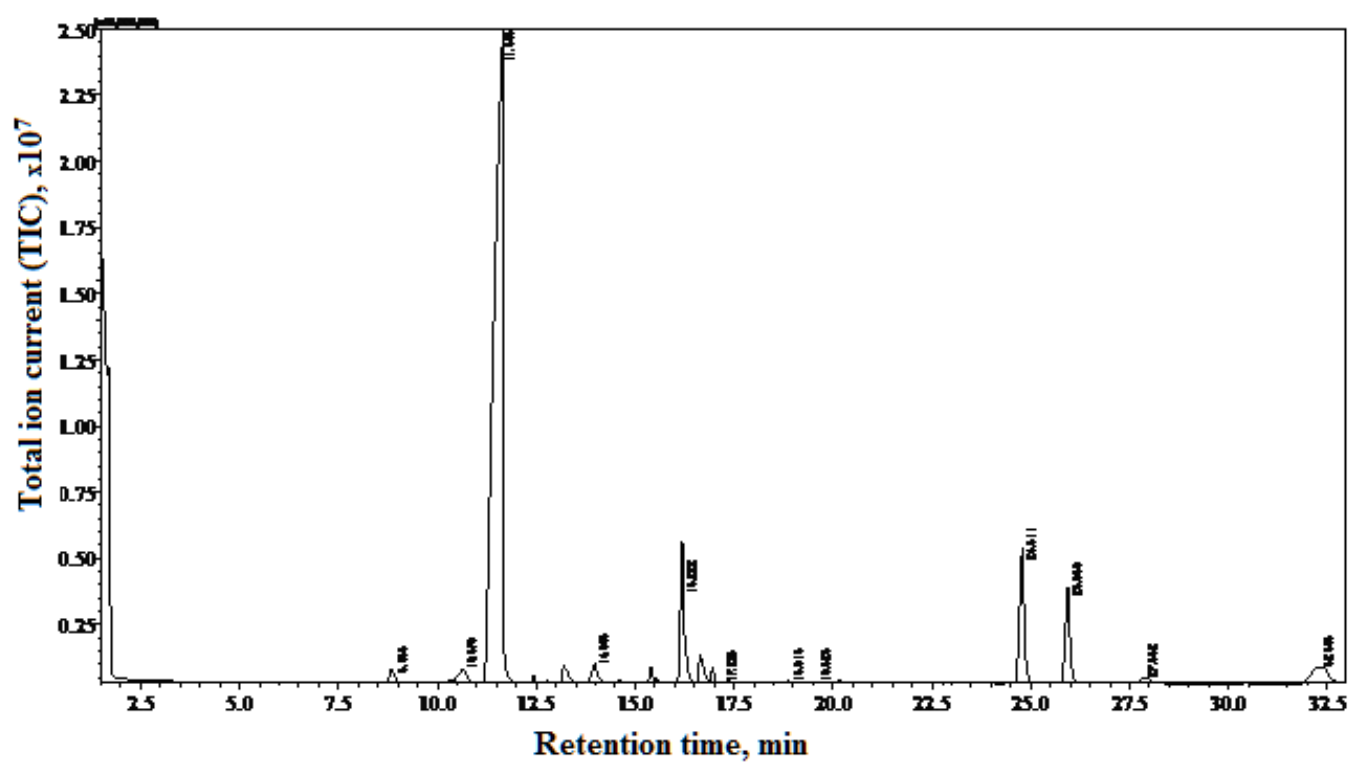

Fig. 2: GC-MS chromatogram of novec 7100 extract

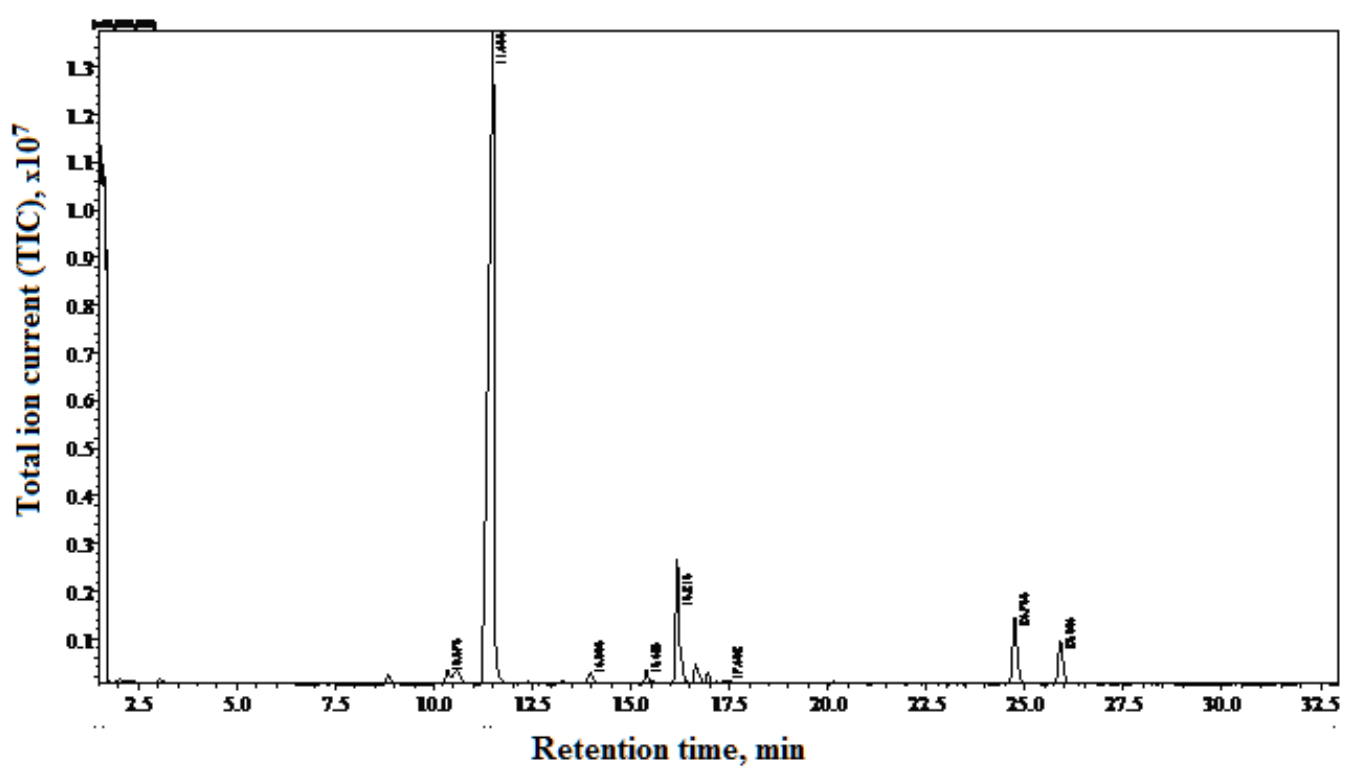

Fig. 3: GC-MS chromatogram of Novec 1230 extract 
Extract compounds' characteristics are presented in table 3.

Table 3: Content of novec 1230/7100 extracts

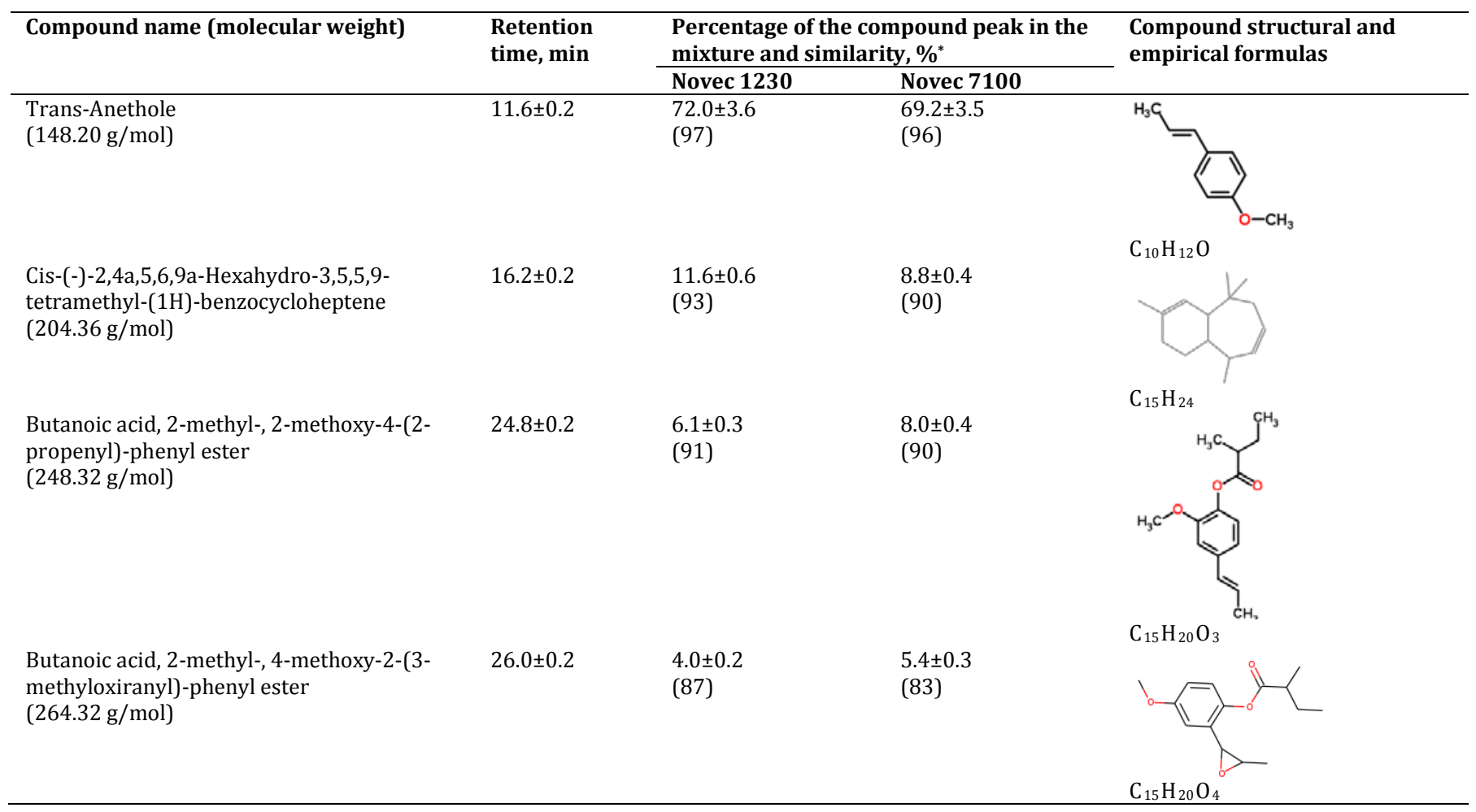

${ }^{*}$ Note. The mean value and its confidence interval (mean \pm SEM) are calculated with repeat counts $n=3$ and significance level $P=0.95$.

As can be seen from the data presented in table 3 , the same compounds are transferred into solvents Novec 1230/7100, and anethole is the dominant component.

Despite the fact that Novec 1230 solvent extracts three times less anethole, it was interesting to study the kinetic of anethole yield from the PRM with using both, Novec 1230 and Novec 7100 by the circulation method of extraction into Soxhlet extractor. In this case, rather poor anethole solubility in Novec 1230 solvent may be compensated by a frequent change of new portions of the extractant.

In the second part of our experiments, we studied the dependence of yield of anethole from the circulation time of Novec 1230/7100 solvents in Soxhlet extractor. The results obtained are presented in fig. 4.

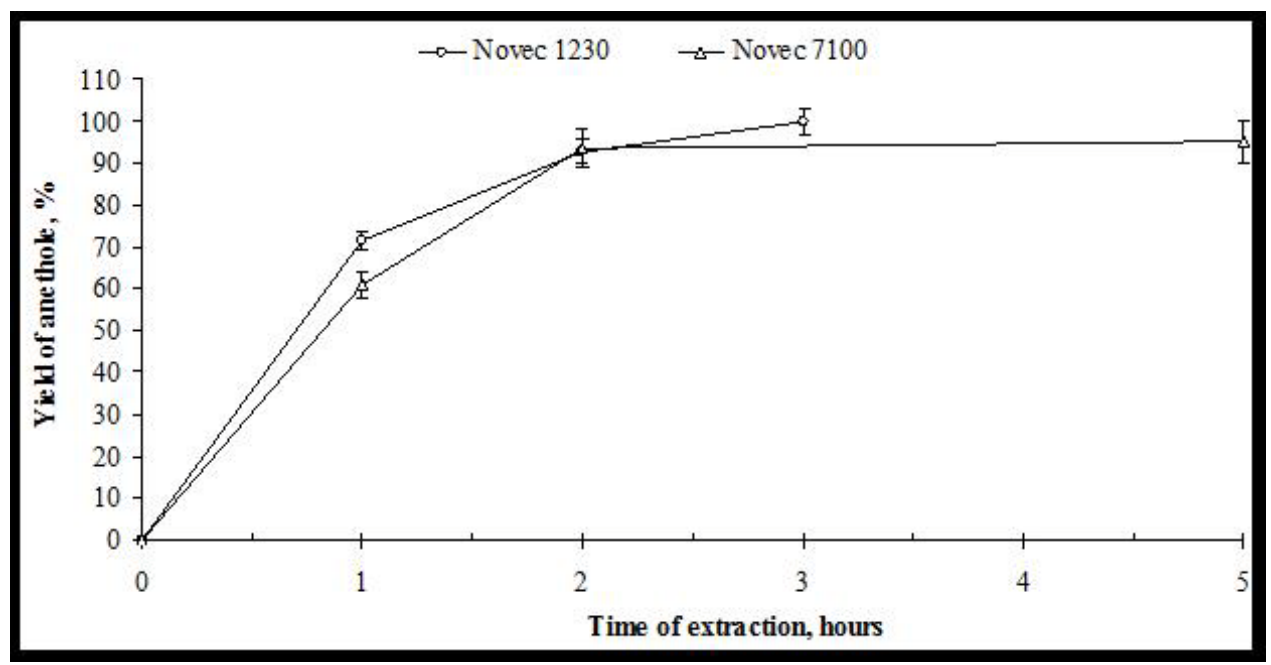

Fig. 4: Dependency of the yield of anethole from the circulation time of Novec $1230 / 7100$ solvent. Repeat counts $n=3$ and significance level $P=0.95$

As can be seen from the experimental curves presented in fig. 4, the yield of anethole under the conditions of the solvent circulation method was up to $94 \pm 5 \%$ within $2 \mathrm{~h}$. These results demonstrate low reasonability of the extraction process using this method for more than $2.5 \mathrm{~h}$. 
It is should be noted that the yield of the lipophilic fraction in comparison to PRM for Novec 1230 solvent was equal to $2.70 \pm 0.14$ $\% \mathrm{w} / \mathrm{w}$, while the content of lipophilic compounds in PRM was equal to $24.1 \pm 1.2 \% \mathrm{w} / \mathrm{w}$. It means that pure essential oil was extracted.

At the same time, under similar conditions of the extraction process, the yield of the lipophilic fraction in comparison to PRM for Novec 7100 solvent was equal to $5.87 \pm 0.29 \% \mathrm{w} / \mathrm{w}$, and the content of anethole in this lipophilic fraction was equal to $32 \%$ by the $2 \mathrm{~h}$.

So, the essential oil obtained is contaminated by vegetable oil (approximately by $50 \%$ ) and it requires an additional stage of purification, for example, with ethanol $96 \%$. According to these results have filed applications for two patents in Russia and Ukraine.

\section{DISCUSSION}

Our results is similar to those by other authors, who extract essential oil from Pimpinella anisum L. fruits using carbon dioxide (for $90 \mathrm{~min}$ at $65 \mathrm{bar}$, the yield of anethole was $89 \%$ and the lipophilic fraction was $11.2 \%$ ) [19], (for $90 \mathrm{~min}$ at $57 \mathrm{bar}$, the yield of the lipophilic fraction was 4.0-4.5\% with anethole content up to $30 \%$ ) [20], as well as using freon 227 ea (for $120 \mathrm{~min}$ at $15 \mathrm{bar}$, the yield of the lipophilic fraction was $5.77 \%$ ).

To summarize the abovementioned information and results of our studies, we can conclude the following some perfluoro organic solvents in accordance with their physical and chemical, toxicological and ecological parameters have better values than freons and are not inferior to carbon dioxide.

These solvents have a key advantage compared to liquefied gases, under common conditions they are liquids with low boiling point temperature $\left(30-80^{\circ} \mathrm{C}\right)$, which means that technology of their use does not require expensive equipment that should work under overpressure.

At the stage of vapor condensation for these solvents, an air refrigerator can be used that has a working range of temperature values within the room values.

The more fluorinated of the solvent molecule, the more significant its lipophobicity and selectivity for dissolution of small low-and/or non-polar molecules of biologically active compounds.

Using perfluoro organic solvents, it is possible to develop the new technology for the selective extraction of essential oils from the essential-oil-bearing plant raw materials.

\section{CONCLUSION}

Adequacy of the working hypothesis about the possibility for extraction of essential oil components from Pimpinella anisum L. fruits by two different perfluoro organic solvents, Novec 1230 and Novec 7100, was verified experimentally. In the context of the solvents tested, it was found that the level of fluorination of the solvent's molecule has a great influence on its extraction properties in regard to anethole and vegetable oil. For the solvent with a maximum level of fluorination (Novec 1230), we observed selective and incomplete yield of anethole, but absolute absence of vegetable oil. For Novec 7100 solvent (a methoxy group is present in its molecule), we observed less selectivity, a more complete yield of anethole, and the presence of vegetable oil up to approximately 50 $\%$. In general, application of perfluoro organic solvents in phytotechnology can be a new-built of development the theory and practice of the extraction process for some types of lipophilic biologically active compounds, including essential oils from the plant raw material.

\section{FINANCIAL SUPPORT AND SPONSORSHIP}

The results were obtained under state grant No. 12.6429.2017/BCh "Complex research of plant-origin objects in the process of creating targeted dosage forms for proctology".

\section{AUTHORS CONTRIBUTIONS}

All the author have contributed equally

\section{CONFLICTS OF INTERESTS}

Conflicts of interest: none declared

\section{REFERENCES}

1. Sidorov II, Turisheva NA, Faleeva LP, Yasnjukevich EI. Technology of natural essential oils and synthetic flavor substances. Moscow: Light and food industries; 1984.

2. Rodrigues VM, Rosa PTV, Marques MOM, Petenate AJ, Meireles MAA. Supercritical extraction of essential oil from aniseed (Pimpinella anisum L.) using CO2: solubility, kinetics, and composition data. J Agric Food Chem 2003;51:1518-23.

3. Dowdle PA, Merseyside SSH, Corr S, Cheshire A, Harris H, Cheshire W. Solvent extraction process. Patent US 2004/ 0105899 A1. A61K 35/78; 2004.

4. Mukhopadhyay M. Natural extracts using supercritical carbon dioxide. 1st ed. Boca Raton: CRC Press; 2000.

5. Santos DT, Meireles MAA. Extraction of volatile oils by supercritical fluid extraction: patent survey. Recent Patents Eng 2011;5:17-22.

6. Georgievskiy VP, Konev FA. Technology and standardization of drugs: a collection of research papers. Kharkov: LLC "RIREG”; 2000.

7. Lemaire B, Mompon B, Surbled I, Surbled M. Method for fractionating essential oils using at least fluorinated solvent. Patent EP 1307533B1. C11B9/025; 2000.

8. Lemaire B, Surbled M, Zwegers J, Mompon B. Method for extracting and fractionating fats with solvent, using at least a hydrofluoroether. Patent US 6673952 B2. C11B 1/00; 2004.

9. Dournel P, Surbled M, Mompon B. Process for separating out at least one organic compound. Patent US 2006/0182689 A1. A61L 9/04, A61K 8/00, C07C 405/00, C07J 9/00, C07C 61/06; 2006.

10. Flick EW. editor. Industrial solvents handbook. 5th ed. Westwood, New Jersey: Noyes data corporation; 1998.

11. Tuma P, Tousignant L. Reducing emissions of PFC heat transfer fluids. 3M. Specialty Materials. St. Paul: 3M; 2002.

12. Barabanov VG, Blinova OV, Zotikov VS, Lizgunov SA, Orlov AP, Orlov GD, et al. Alternative ozone safe propellants, freons, foaming agent, solvents, and fire-extinguishing agents. Moscow; 2002.

13. Isikava NI. editor. New in the technology of fluorinated compounds. Moscow: Mir; 1984.

14. Popova NV, Litvinenko VI, Kucanjan AS. Medicinal plants of the world: Encyclopedic Handbook. Kharkov: Disa Plus; 2016.

15. El-hodairy FA. Neuroprotective effects of Pimpinella anisum on normal and diabetic rats. Int J Pharm Pharm Sci 2014;6:9-12.

16. Gupta D, Girija. Evaluation of in vitro antioxidant and antimicrobial activities of various spices of Indian origin. Int J Pharm Pharm Sci 2015;8:137-41.

17. European Pharmacopoeia. 8th ed. Strasbourg: European Directorate for the Quality of Medicines and HealthCare; 2014.

18. Zhilyakova ET, Novikov OO, Pisarev DI, Malyutina AY, Boyko NN. Studying the polyphenolic structure of Laurus Nobilis L. leaves. Indo Am J Pharm Sci 2017;4:3066-74.

19. Tuan DQ, Ilangantileket SG. Liquid CO2 extraction of essential oil from Star anise fruits (Illicium verum H.). J Food Eng 1997;31:47-57.

20. Kasianov GI, Pekhov AV, Taran AA. Natural food flavors-CO2 extracts. Moscow: Food industries; 1978. 